\title{
Work-Related Traumatic Injuries and Associated Risk Factors in Iranian Metal Melting Workers, 2016
}

\author{
Zahra Asadi ${ }^{1}$, Hossein Akbari ${ }^{2}$, Alireza Dehdashti ${ }^{3}$, Milad Motalebi Kashani ${ }^{4}$, Hamidreza Saberi ${ }^{1}$ and \\ Masoud Motalebi Kashani ${ }^{5, *}$ \\ ${ }^{1}$ Environment Engineering Department, Islamic Azad University, Central Branch of Tehran, Tehran, Iran \\ ${ }^{2}$ Biostatistics and Epidemiology Department, Health Faculty, Kashan University of Medical Sciences, Kashan, Iran \\ ${ }^{3}$ Social Determinants of Health Research Center, Semnan University of Medical Sciences, Semnan, Iran \\ ${ }^{4}$ New York College of Podiatric, New York, USA \\ ${ }^{5}$ Social Determinants of Health Research Center, Kashan University of Medical Sciences, Kashan, Iran \\ "Corresponding author: Social Determinants of Health Research Center, Kashan University of Medical Sciences, Kashan, Iran. Tel: +98-3155540111, Email: \\ motallebi_m@kaumc.ac.ir \\ Received 2017 December 24; Revised 2018 March 12; Accepted 2018 April 27.
}

\begin{abstract}
Background: Traumatic injuries are a leading cause of death and disability in the working population, worldwide. According to estimates, by 2020 , traumatic injuries will be the second cause of disability in developing countries and the third cause of death and disability across nations, worldwide.

Objectives: This study aimed at assessing work-related traumas and related risk factors that may contribute to the development of injuries among Iranian metal melting workers in Kashan industrial sites.

Methods: Data were collected by a descriptive cross-sectional study on 178 Iranian metal melting workers in five manufacturing sites of Kashan, selected as a census. The data consisted of a three-year period from 2014 to 2016. Samples were selected as the census. The study used a demographic questionnaire, accident investigation reports, and interviews with workers that had experienced traumatic injuries, to collect data.

Results: Overall, $58.43 \%$ of workers experienced traumatic events. The data indicated a significant association between ages, years of employment, and being a witness of an accident with work-related trauma $(\mathrm{P}<0.05)$. Workers involved in smelting operations experienced more injuries than workers at other processing units. Most Injuries affected hands and wrists. The leading causes of work-related injuries were contacting with hot objects (42.3\%), fall from height (26.9\%), electrical shock (1.9\%), strike (18.3\%), stuck (3.8\%), and strain (1.9\%).

Conclusions: These results may contribute to the nature of tasks in metal melting process, requiring the performance of hot processes and heavy manual tasks with hand tools. The results provide steps for developing prevention strategies. Metal workers involved in performing hot processes and heavy manual tasks might be considered as first targets for preventive interventions.
\end{abstract}

Keywords: Heavy, Industry, Injuries, Melting, Metals, Occupational, Worker, Work Related

\section{Background}

Industrialization and harsh work environments have caused increased work-related accident rates, particularly in developing nations (1). Traumatic incidents and injuries are leading causes of death and disability in the working population, worldwide. According to estimates, by 2020 , traumatic injuries will be the second cause of disabilities in developing countries and the third cause of death and disability across nations worldwide. Injuries due to traumatic accidents account for $12 \%$ of diseases, involving the highest mortality rates of unintentional mortalities (2). Reports from the International Labor Organization indi- cated that trauma attributed to one-third of work-related deaths. Additionally, 250 million work-related traumas occur annually with an average annual fatality rate of 14 per 100000 workers per year (3). Accidents result in a million work-days losses (4). An occupational accident is defined as an unplanned and unexpected incident during work, resulting in injury, illness, and death (5). In Iran, the number of occupational accidents was 15520 in 2000 and 16745 in 2003 , indicating an increase of $7.67 \%$ (6). The mortality related to traumatic injuries in every 100000 population was reported as 39 cases in Iran, compared to 88 cases around the world (7). 
Given the remarkable incurred social and economic costs associated with work-related traumatic injuries, efforts to better understand and provide prevention and surveillance systems have increased in recent years $(8,9)$. Review of the literature revealed a number of epidemiological studies on occupational trauma injuries, such as Chi et al. (10, 11), Jeong (12), Aladelusi et al. (13), Gupta et al. (14), Zimmerman et al. (15), and Bylund and Björnstig (16).

Meanwhile, previous research has indicated the high prevalence of accidents in the metal industry, which contributed to the hazardous working process. Traumatic Burning and eye injuries were common in the metal industry, mainly caused by melted fluid splash, falling in the container, falling objects, and explosion (17).

\section{Objectives}

An epidemiologic pattern of work-related trauma injuries in the Iranian metal industry has not been welldocumented. In addition, reducing traumatic injuries remains significant because of serious outcomes faced by workers who sustain one. Therefore, the primary purpose of the current study was to identify work-related traumas and related risk factors that may contribute to the development of injuries among Iranian metal melting workers in Kashan industrial sites.

\section{Methods}

\subsection{Study Design and Participants}

Data were collected in a descriptive cross-sectional survey on process workers in Kashan metal melting industry. The study sample consisted of 178 workers at five manufacturing sites. Samples were selected as a census. The list of workers was provided by the human resources center of these industries. The data were collected over a three-year time period from the year 2014 to 2016.

\subsection{Ethics}

The participants received occupational safety information sheets from health offices located in the plants, explaining the scope and the purpose of the study with clear guidance to attend the survey or exit at that point. All participants were ensured about the confidentiality of the individually identifiable data.

\subsection{Instruments and Procedure}

The study applied a demographic questionnaire, accident investigation reports, and interviews with workers, who had experienced traumatic injuries to collect data. Occupational safety and health offices in the plant sites invited workers to participate in the study.

A questionnaire developed by the research team was used to collect demographic data including age, gender, marital status, height, type of employment, shift work, duration of employment, place of work, shift work, secondary job, education, smoking, job satisfaction, working hours, and training in occupational safety and health.

Work-related traumatic data were collected from accident investigation reports databases, maintained by the occupational health and safety administration of the studied sites (private section). The researchers collected data concerning the type and severity of accidents; including parts of the body injured and related risk factors.

Workers, who experienced accidents, were interviewed. All interview sessions were conducted individually. Gathering data from accident investigation reports and interview with workers was done by a postgraduate candidate in health and safety. The interviewer greeted each subject and explained the purpose of the study. Particular attention was paid to the experienced traumatic incidence, the severity of the trauma, first aids and treatment received the following incidence and duration of recovery.

\subsection{Data Analyses}

Data were analyzed by the chi-square test, $t$-test, analysis of variance, and the logistic regression model for multivariate analyses. P values of $<0.05$ were considered statistically significant. Statistical analyses were performed using the SPSS Statistics for Windows, version 16.0 (SPSS Inc., Chicago, ILL., USA).

\section{Results}

Of 178 metal workers exposed directly to melting process operation, 104 workers experienced traumatic events. Participants' age was between 19 and 55. Workers were involved in various operations, including smelting process unit (46.6\%), Perapersy(18.5\%), maintenance (14.1\%), insulating (6.7\%), and tensile unit (7.3\%).

Nearly one-third of all participants had some university education, $44.9 \%$ completed high school diploma, and $26.4 \%$ had an elementary and secondary education. Most of the participants had a rotatory shift work schedule 
(72.5\%). Nearly half of the workers reported being satisfied with their jobs (46.6\%), and $83.7 \%$ were not involved in a secondary job. Most had received health and safety at work training (76.4\%), and professional training related to their job procedures (73.6\%). Workers with smoking habits were $12.9 \%$. Workers with a usual working shift of eight hours made up $69.7 \%$ of the sample, while for around one-third the working schedule exceeded 12 hours.

Overall, more than half of the workers (58.4\%) experienced work-related traumatic events. The data revealed that almost one-quarter of workers had suffered trauma only once and $32 \%$ between two to fifteen times.

Tables 1 and 2 present the figures and percentages in terms of work-related trauma, individual, and occupational characteristics. The data indicated a significant association between age, years of employment, and being a witness of an accident with work-related trauma $(\mathrm{P}<0.05)$. However, no statistical relationships were determined for other studied individual and occupational variables and experience of trauma.

Figure 1 shows the percentages of work-related trauma in terms of the work unit, nature of the injury event, and the body part affected. Injuries occurred in the smelting operation unit were higher than the other processing units. While burning injury due to contact with hot objects was the most frequent type of injury, most Injuries affected hands and wrists.

The mean and standard deviations of treatment duration are shown in Table 3. Those, who had received training in occupational safety and health, had a lower duration of treatment $(\mathrm{P}<0.05)$. However, individual and occupational factors were not statistically associated with duration of treatment. Table 4 presents the results of multiple regression analysis, evaluating the relationships adjusted for potential factors. Age, place of work and attendance at the accident scene significantly affected work-related traumatic injuries.

\section{Discussion}

This paper provides the epidemiologic outline of workrelated traumatic injuries in the Iranian metal melting industry. Overall, the results indicated that a substantial prevalence of traumatic incidence (58.4) leads to injuries in workers involved in the metal melting process.

This study revealed that married workers had a higher risk of traumatic injuries; it could be suggested that due to their responsibility and lack of job security they exposed themselves to increased risks. Some previous studies, including Atrkar Roshan et al. (5) indicated an increased risk of accident rate among married workers, performing the more physically demanding job tasks.

Apparently, hazardous working environments, particularly crowded and disordered equipment and machinery and harsh climatic conditions, may contribute to increased risk of injury events in smelting operations.

The current study suggests higher traumatic incidence in workers with elementary education. This is in agreement with Khanzade et al.'s study that concluded that better education resulted in higher risk perception (18).

This study indicated increases in both accident frequency and traumatic injury rates among rotating shift workers, which may be related to chronic fatigue and deteriorated concentration on tasks (19).

In the current study, workers, who were more satisfied with their job, were more likely to suffer traumatic injuries. A previous study found that people with higher levels of job satisfaction are more likely to take risky jobs (20).

The current finding showed that although occupational safety and health training did not decrease the rates of traumatic incidence, yet it might contribute to the decreased severity of suffered injury and rehabilitation period. Previous studies suggested that inexperienced workers were exposed to high risks of accidents (10-12).

The present study indicated workers aged between 19 and 35 years had an increased risk of work-related traumatic injury, which is in agreement with the results of workplace injury rate among workers in the Iranian Aluminum production industry (21). Another occupational injury study demonstrated higher injury incidence rates among workers aged 21 to 30 (13). Other studies have reported elevated occupational injury rates among younger workers $(14,15,22)$. These analyses show that young workers experienced more work-related traumatic injuries. Associated factors may include performing high-risk activities among younger workers (7, 13, 14, 21). Additionally, this study showed an increased risk of traumatic injuries among workers with more than 11 years of employment, probably due to ignoring workplace safety regulations and procedures.

Meanwhile, observing accidents on-site had made workers less vulnerable, probably due to reflective actions leading to obeying of safety rules and protecting against injury incidence (23). In another study from the United States, the severity of hand injuries, especially the fingers, after the strains of the legs and back, was the most severe disability (22). In Italy, $40 \%$ of workers had carpal tunnel 


\begin{tabular}{|c|c|c|c|c|c|}
\hline Individual Characteristics & Without Trauma $^{\mathrm{a}}$ & With Trauma $^{\mathrm{a}}$ & Total $^{\mathrm{a}}$ & OR $(95 \% \mathrm{CI})$ & PValues \\
\hline Marital status & & & & $1.398(0.642,3.039)$ & 0.39 \\
\hline Single & $15(20.3)$ & $16(15.4)$ & $31(17.4)$ & & \\
\hline Married & $59(79.7)$ & $88(84.6)$ & $147(82.6)$ & & \\
\hline Smoking & & & & $0.890(0.363,2.178)$ & 0.79 \\
\hline Yes & $9(12.2)$ & $14(13.5)$ & $23(12.9)$ & & \\
\hline No & $65(87.8)$ & $90(86.5)$ & $155(87.1)$ & & \\
\hline Secondary job & & & & $1.385(0.623,3.576)$ & 0.42 \\
\hline Yes & $14(18.9)$ & $15(14.4)$ & $29(16.3)$ & & \\
\hline No & $60(81.1)$ & $89(85.6)$ & $149(83.7)$ & & \\
\hline Education & & & & & 0.50 \\
\hline Primary school & $5(6.8)$ & $6(5.8)$ & $11(6.2)$ & - & \\
\hline Junior school & $14(18.9)$ & $22(21.2)$ & $36(20.2)$ & $1.31(0.34,5.10)$ & \\
\hline High school & $30(40.5)$ & $51(49)$ & $81(45.5)$ & $1.42(0.398,5.04)$ & \\
\hline Academic & $25(33.8)$ & $25(24)$ & $50(28.1)$ & $0.833(0.225,3.09)$ & \\
\hline Age, $y$ & & & & $2.287(1.234,4.238)$ & 0.008 \\
\hline $19-34$ & $49(66.2)$ & $48(46.2)$ & $97(54.5)$ & & \\
\hline $35-55$ & $25(33.8)$ & $56(53.8)$ & $81(45.5)$ & & \\
\hline Years of employment, $y$ & & & & $2.201(1.198,4.045)$ & 0.010 \\
\hline$<9$ & $45(60.8)$ & $43(41.3)$ & $88(49.4)$ & & \\
\hline$>10$ & $29(39.2)$ & $61(58.7)$ & $90(50.6)$ & & \\
\hline \multicolumn{6}{|l|}{$\begin{array}{l}\text { Abbreviation: OR, Odds Ratio. } \\
{ }^{\mathrm{a}} \text { Values are expressed as No. (\%). }\end{array}$} \\
\hline Job Characteristics & Without Trauma $^{a}$ & With Trauma ${ }^{a}$ & Total $^{\mathbf{a}}$ & OR $(95 \% \mathrm{CI})$ & PValues \\
\hline Shift work schedule & & & & $1.036(0.522,2.056)$ & 0.91 \\
\hline Morning & $19(25.7)$ & $26(25)$ & $45(25.3)$ & & \\
\hline Rotational & $55(74.3)$ & $78(75)$ & $133(74.7)$ & & \\
\hline Job satisfaction & & & & & 0.08 \\
\hline Never & $6(8.1)$ & $4(3.8)$ & $10(5.6)$ & - & \\
\hline low & $1(1.4)$ & $8(7.7)$ & $9(5.1)$ & $12(1.05,136.7)$ & \\
\hline Medium & $28(37.8)$ & $48(46.2)$ & $76(42.7)$ & $2.57(0.668,0.99)$ & \\
\hline High & $39(52.7)$ & $44(42.3)$ & $83(46.6)$ & $1.69(0.445,6.44)$ & \\
\hline Safety and health training & & & & $0.724(0.361,1.453)$ & 0.36 \\
\hline Yes & $54(73)$ & $82(78.8)$ & $136(76.4)$ & & \\
\hline No & $20(27)$ & $22(21.2)$ & $42(23.6)$ & & \\
\hline Job training & & & & $1.203(0.607,2.380)$ & 0.59 \\
\hline Yes & $56(75.5)$ & $75(72.1)$ & $131(73.6)$ & & \\
\hline No & $18(24.3)$ & $29(27.9)$ & $47(26.4)$ & & \\
\hline Working hours schedules & & & & $0.680(0.357,1.296)$ & 0.32 \\
\hline 8 hours & $48(64.9)$ & $77(74.1)$ & $125(70.7)$ & & \\
\hline 12 hours & $26(35)$ & $27(26)$ & $53(30.2)$ & & \\
\hline Witnessing incidence & & & & $2.071(1.129,3.797)$ & 0.018 \\
\hline Yes & $33(44.6)$ & $65(62.5)$ & $98(55.1)$ & & \\
\hline No & $41(55.4)$ & $39(37.5)$ & $80(44.9)$ & & \\
\hline
\end{tabular}

Abbreviation: OR, Odds Ratio.

${ }^{\mathrm{a}}$ Values are expressed as No. (\%).

syndrome, and 32\% had Tigger Finger (24).

The current study revealed the hands and wrists as the 


\begin{tabular}{|c|c|c|}
\hline Variable & Days of Hospitalization, Mean \pm SD & P Value \\
\hline Marital status & & 0.70 \\
\hline Single & $1.37 \pm 2.55$ & \\
\hline Married & $1.85 \pm 4.84$ & \\
\hline Smoking & & 0.31 \\
\hline Yes & $2.92 \pm 6.45$ & \\
\hline No & $1.60 \pm 4.21$ & \\
\hline Second job & & 0.82 \\
\hline Yes & $1.53 \pm 3.81$ & \\
\hline No & $1.82 \pm 4.69$ & \\
\hline Education & & 0.43 \\
\hline Primary school & $1.16 \pm 1.32$ & \\
\hline Junior school & $0.86 \pm 1.12$ & \\
\hline High school & $2.52 \pm 6.23$ & \\
\hline Academic & $1.20 \pm 2.12$ & \\
\hline Age, $y$ & & 0.48 \\
\hline $19-34$ & $1.43 \pm 3.85$ & \\
\hline $35-55$ & $2.07 \pm 5.10$ & \\
\hline Years of employment, $y$ & & 0.50 \\
\hline$<9$ & $1.41 \pm 4.60$ & \\
\hline$>10$ & $2.03 \pm 4.90$ & \\
\hline Safety training & & 0.04 \\
\hline Yes & $1.41 \pm 3.87$ & \\
\hline No & $3.13 \pm 6.46$ & \\
\hline Job training & & 0.0 \\
\hline Yes & $1.02 \pm 2.03$ & \\
\hline No & $3.72 \pm 7.76$ & \\
\hline Shift work & & 0.26 \\
\hline Morning & $2.65 \pm 6.85$ & \\
\hline Rotational & $1.48 \pm 3.50$ & \\
\hline Job Satisfaction & & 0.29 \\
\hline Never & $0.0 \pm 0.0$ & \\
\hline low & $0.87 \pm 1.35$ & \\
\hline Average & $1.11 \pm 2.44$ & \\
\hline High & $2.68 \pm 6.18$ & \\
\hline Working hours & & 0.09 \\
\hline 8 hours & $1.32 \pm 2.95$ & \\
\hline 12 hours & $3.00 \pm 7.28$ & \\
\hline Witnessing incidence & & 0.29 \\
\hline Yes & $1.41 \pm 3.34$ & \\
\hline No & $2.38 \pm 6.08$ & \\
\hline
\end{tabular}

\begin{tabular}{|c|c|c|c|c|c|}
\hline \multirow{2}{*}{ Variables } & \multicolumn{5}{|c|}{ Regression Parameters } \\
\hline & B & SD & Wald & $\operatorname{EXP}(\mathbf{B})$ & PValue \\
\hline Age & 0.062 & 0.026 & 5.73 & 1.06 & 0.017 \\
\hline Technical work unit & 1.33 & 0.63 & 4.44 & 3.81 & 0.035 \\
\hline Refractory work unit & -1.45 & 0.73 & 3.94 & 0.23 & 0.047 \\
\hline Witnessing incidence & 0.67 & 0.33 & 4.23 & 1.97 & $<s s 0.000$ \\
\hline
\end{tabular}


A

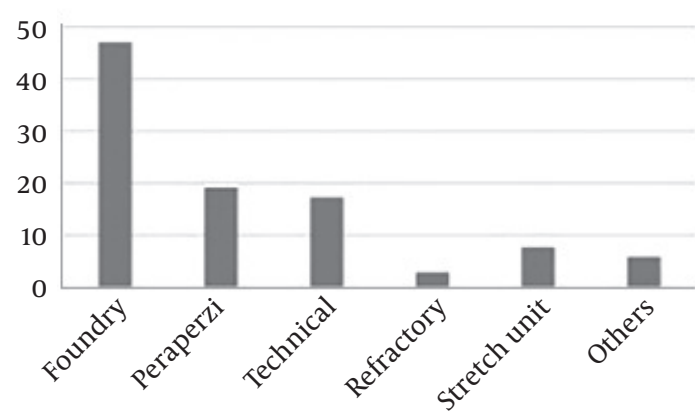

C

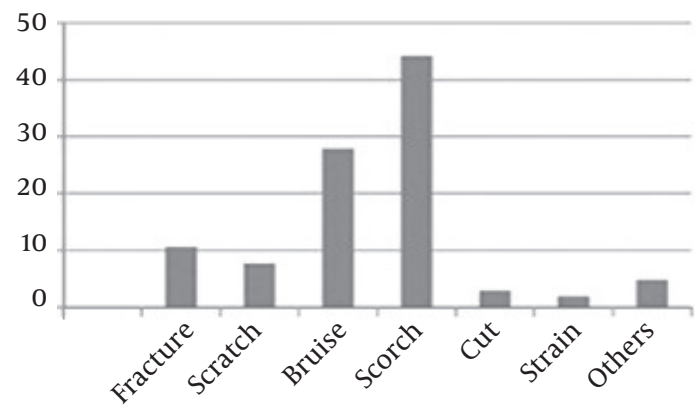

\section{B}

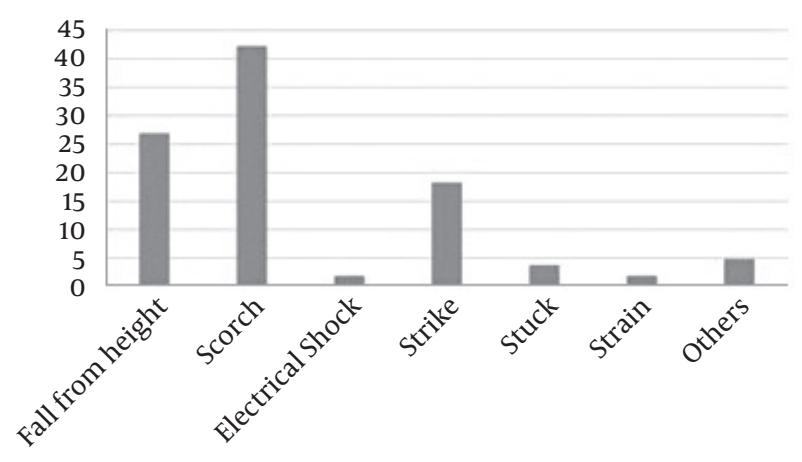

D

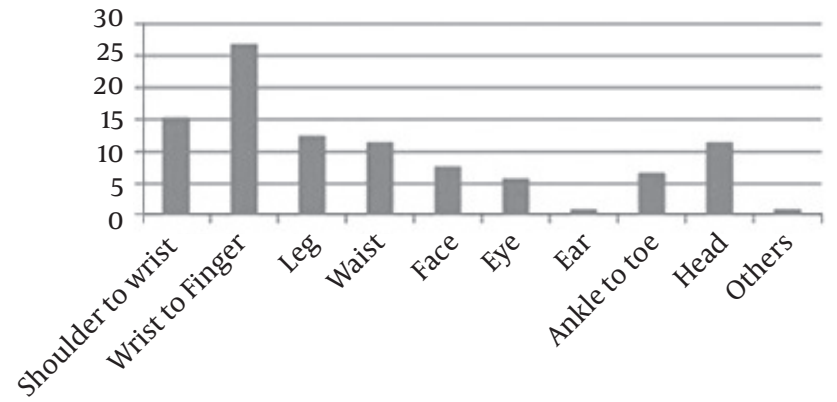

Figure 1. Frequency of traumatic work-related injuries among mental melting workers from 2014 to 2016; (A, work unit; B, incidence type; C, injury type; D, injured body part)

most prevalent body sites affected following traumatic injuries, which is similar to the results reported by Muhammadfam (21) and Bylund and Björnstig (16). Also, in a study that investigated occupational injuries in an emergency trauma unit, falling was 25 percent the most (25).

The current results also indicated that burning was the most frequent traumatic injuries followed by fall-related incidence. These results may contribute to the nature of tasks in metal melting process, requiring the performance of hot processes and heavy manual tasks with hand tools.

The current findings are important because they described the extent of traumatic injuries occurring in metal melting processing plants and at-risk workers in terms of demographic and occupational characteristics. These results provide the first steps for the development of prevention strategies.

One limitation of the current study was that the authors had limited information on factors, such as exposure to physical work conditions, safety and health practices, and use of personal protective equipment. Although this study provides an epidemiologic description of workrelated injuries in metal melting industry, yet it does not provide data on the whole scope of traumatic injuries at workplaces. Future studies should consider the above factors, which may lead to effective prevention strategies.

\section{Acknowledgments}

This article was based on a student dissertation on health, safety and environment management with approval number 10140425942012 at Tehran Azad University, Central Branch. The authors are thankful to Health Deputy at Kashan University of Medical Sciences and all occupational safety and health consultants employed in these industries and workers, who participated in this study.

\section{References}

1. Cheng CW, Leu SS, Lin CC, Fan C. Characteristic analysis of occupational accidents at small construction enterprises. Saf Sci. 2010;48(6):698-707. doi:10.1016/j.ssci.2010.02.001. 
2. Maracy MR, Tabar Isfahani M. [The burden of road traffic injuries in Isfahan, Iran in 2010]. J Kerman Univ Med Sci. 2013;20(5). Persian.

3. Shalini RT. Economic cost of occupational accidents: Evidence from a small island economy. Saf Sci. 2009;47(7):973-9. doi: 10.1016/j.ssci.2008.10.021.

4. Manzey D, Marold J. Occupational accidents and safety: The challenge of globalization. Saf Sci. 2009;47(6):723-6. doi: 10.1016/j.ssci.2008.01.013.

5. Atrkar Roshan S, Alizadeh SS. [Estimate of economic costs of accidents at work in Iran: A case study of occupational accidents in 2012]. Iran Occup Health. 2015;12(1):12-9. Persian.

6. Nouri J, Azadeh A, Mohammad Fam I. The evaluation of safety behaviors in a gas treatment company in Iran. J Loss Prev Process Ind. 2008;21(3):319-25. doi:10.1016/j.jlp.2007.11.006.

7. Azizi A, Abdoli GH. Mortality rates in Kermanshah province-2000. J Kermanshah Univ Med Sci. 2003;7(3):10-7.

8. Mackersie RC. Field triage, and the fragile supply of "optimal resources" for the care of the injured patient. Prehosp Emerg Care. 2006;10(3):347-50. doi: 10.1080/10903120600728920. [PubMed: 16801277].

9. Schuur JD, Hsia RY, Burstin H, Schull MJ, Pines JM. Quality measurement in the emergency department: Past and future. Health Aff (Millwood). 2013;32(12):2129-38. doi: 10.1377/hlthaff.2013.0730. [PubMed: 24301396].

10. Chi CF, Chen CL. Reanalyzing occupational fatality injuries in Taiwan with a model free approach. Saf Sci. 2003;41(8):681-700. doi: 10.1016/s0925-7535(02)00018-8.

11. Chi C, Yang C, Chen Z. In-depth accident analysis of electrical fatalities in the construction industry. International Journal of Industrial Ergonomics. 2009;39(4):635-44. doi: 10.1016/j.ergon.2007.12.003.

12. Jeong BY. Occupational deaths and injuries in the construction industry. Appl Ergon. 1998;29(5):355-60. doi: 10.1016/S0003-6870(97)00077X. [PubMed: 9703349].

13. Aladelusi TO, Akinmoladun IV, Olusanya OO, Akadiri OA, Fasola AO. Evaluation of pedestrian road traffic maxillofacial injuries in a Nigerian tertiary hospital. Afr J Med Med Sci. 2014;43(4):353-9. [PubMed: 26234124].

14. Gupta S, Wong EG, Nepal S, Shrestha S, Kushner AL, Nwomeh BC, et al. Injury prevalence and causality in developing nations: Results from a countrywide population-based survey in Nepal. Surgery. 2015;157(5):843-9. doi: 10.1016/j.surg.2014.12.020. [PubMed: 25934021].

15. Zimmerman K, Jinadasa D, Maegga B, Guerrero A. Road traffic injury on rural roads in Tanzania: Measuring the effectiveness of a road safety program. Traffic Inj Prev. 2015;16(5):456-60. doi: 10.1080/15389588.2014.973491. [PubMed: 25356935].

16. Bylund PO, Björnstig U. Occupational injuries and their long term consequences among mechanics and construction metal workers. Saf Sci.1998;28(1):49-58. doi:10.1016/s0925-7535(97)00070-2.

17. Bahrami A. A guide to occupational health in foundries. Environmental and occupational health center. Tehran University of Medical Sciences. Institute for Environmental Research; 2012. Persian.

18. Khanzode VV, Maiti J, Ray PK. Occupational injury and accident research: A comprehensive review. Saf Sci. 2012;50(5):1355-67. doi: 10.1016/j.ssci.2011.12.015.

19. Ferri P, Guadi M, Marcheselli L, Balduzzi S, Magnani D, Di Lorenzo R. The impact of shift work on the psychological and physical health of nurses in a general hospital: A comparison between rotating night shifts and day shifts. Risk Manag Healthc Policy. 2016;9:20311. doi: 10.2147/RMHP.S115326. [PubMed: 27695372]. [PubMed Central: PMC5028173].

20. Sunal AB, Sunal O, Yasin F. A comparison of workers employed in hazardous jobs in terms of job satisfaction, perceived job risk and stress: Turkish jean sandblasting workers, dock workers, factory workers and miners. Soc Indic Res. 2010;102(2):265-73. doi: 10.1007/s11205-0109679-3.

21. Mohammadfam I. [Occupational accident and connected factors analysis in a factory in Arak]. Scientific Med J Kordestan. 2001;5(42):1936. Persian.

22. Sorock GS, Lombardi DA, Courtney TK, Cotnam JP, Mittleman MA. Epidemiology of occupational acute traumatic hand injuries: A literature review. Saf Sci. 2001;38(3):241-56. doi: 10.1016/s09257535(01)00004-2.

23. Wachter JK, Yorio PL. A system of safety management practices and worker engagement for reducing and preventing accidents: An empirical and theoretical investigation. Accid Anal Prev. 2014;68:117-30. doi: 10.1016/j.aap.2013.07.029. [PubMed: 23993683].

24. Barbieri PG, Colombini D, Occhipinti E, Vigasio A, Poli R. [Epidemics of musculotendinous pathologies of the upper limbs (cumulative trauma disorders) in a group of assembly line workers]. Med Lav. 1993;84(6):487-500. Italian. [PubMed: 8177134].

25. Macdonald DJ, Sanati KA, Macdonald EB. The costs and characteristics of occupational injuries admitted to a trauma unit. Int J Occup SafErgon.2012;18(4):587-90. doi:10.1080/10803548.2012.11076961. [PubMed: 23294664]. 